Article

\title{
Application of a Heat Flux Sensor in Wind Power Electronics
}

\author{
Elvira Baygildina ${ }^{1, *}$, Liudmila Smirnova ${ }^{1}$, Kirill Murashko ${ }^{1}$, Raimo Juntunen ${ }^{1}$, \\ Andrey Mityakov ${ }^{1}$, Mikko Kuisma ${ }^{1}$, Olli Pyrhönen ${ }^{1}$, Pasi Peltoniemi ${ }^{1}$, Katja Hynynen ${ }^{1}$, \\ Vladimir Mityakov ${ }^{2}$ and Sergey Sapozhnikov ${ }^{2}$ \\ 1 Department of Electrical Engineering, Lappeenranta University of Technology, P.O. Box 20, \\ Lappeenranta FI-53851, Finland; liudmila.n.popova@gmail.com (L.S.); kirill.murashko@lut.fi (K.M.); \\ raimo.juntunen@lut.fi (R.J.); andrey.mityakov@lut.fi (A.M.); mikko.kuisma@lut.fi (M.K.); \\ olli.pyrhonen@lut.fi (O.P.); pasi.peltoniemi@lut.fi (P.P.); katja.hynynen@lut.fi (K.H.) \\ 2 Department of Thermodynamics and Heat Transfer, Saint-Petersburg State Polytechnical University, \\ Polytechnicheskaya 29, Saint-Petersburg 195251, Russia; mitvlad@mail.ru (V.M.); \\ serg.sapozhnikov@mail.ru (S.S.) \\ * Correspondence: elvira.baygildina@lut.fi; Tel.: +358-465-999-902
}

Academic Editor: Sukanta Basu

Received: 1 February 2016; Accepted: 6 June 2016; Published: 14 June 2016

\begin{abstract}
This paper proposes and investigates the application of the gradient heat flux sensor (GHFS) for measuring the local heat flux in power electronics. Thanks to its thinness, the sensor can be placed between the semiconductor module and the heat sink. The GHFS has high sensitivity and yields direct measurements without an interruption to the normal power device operation, which makes it attractive for power electronics applications. The development of systems for monitoring thermal loading and methods for online detection of degradation and failure of power electronic devices is a topical and crucial task. However, online condition monitoring (CM) methods, which include heat flux sensors, have received little research attention so far. In the current research, an insulated-gate bipolar transistor (IGBT) module-based test setup with the GHFS implemented on the base plate of one of the IGBTs is introduced. The heat flux experiments and the IGBT power losses obtained by simulations show similar results. The findings give clear evidence that the GHFS can provide an attractive condition monitoring method for the thermal loading of power devices.
\end{abstract}

Keywords: heat flux sensor; measurement; power electronics; reliability; wind turbine

\section{Introduction}

Alongside the growing complexity and power density of the modern power systems, the thermal management of these systems becomes crucial. A considerable proportion of the power loss in the system is converted into heat, which leads to a temperature rise of the power components. An insulated-gate bipolar transistor (IGBT) power module as a key component of the wind power converter is particularly prone to a number of potential failure modes because of the thermal stress. As it experiences high voltages and currents, the IGBT module suffers from high switching and conduction losses. Moreover, such extreme conditions as wind gusts and high reactive power injection during low-voltage ride-through can significantly increase the losses [1,2].

Power cycles generated in the IGBT module induce local temperature excursions over the multilayered structure of the device. Besides the vertical temperature gradient due to the thermal resistance of the module at a steady state, the dynamic temperature excursions of different magnitudes take place between the layers due to the different thermal capacitances of the materials. The latter causes the cyclic thermo-mechanical stress in the module, which induces wear-out mechanisms. The research of the failure mechanisms caused by the reason of different thermal expansion properties 
is carried out in [3-6]. However, the structural deformation of the module and the change in thermal parameters of the device result in changed heat conduction properties and the heat flux distribution pattern in the IGBT module.

To ensure a high reliability performance of the component, efficient measurement tools and an appropriate design of the cooling system are needed. Currently, the IGBT junction temperature measurement methods, such as optical methods, temperature sensors implemented inside the module, and methods applying temperature sensitive electrical parameters (TSEP), are widely studied. The use of the optical methods (infrared (IR) sensors, optical fibers, IR microscope, and IR camera) gives the possibility of capturing a device temperature map. However, the optical systems cannot be used if the device is packaged. Thus, it is not possible to perform online temperature measurement during the device operation. Considering the physical contact methods, temperature sensors are usually soldered onto the chip or mounted on the direct copper bonded (DCB) substrate. Depending on the type of physical contact, either the point or multiple, the sensors can provide the local or spatial temperature measurements. The disadvantage of the physical contact method is the need for a mechanical access to the chip $[7,8]$. The TSEP methods use the predefined relationship between the electrical parameters, such as the internal gate resistance $R_{\text {Gint }}$, the collector-emitter saturation voltage $V_{\text {CEsat }}$, the gate-emitter voltage $V_{\mathrm{GE}}$ or the saturation current $I_{\text {sat, }}$ and the IGBT junction temperature $[7,9,10]$. However, the TSEP approach involves implementation of additional measurement circuitry and a need for calibration.

Considering conventional methods of estimating the IGBT loss, high-precision estimation of the IGBT on-state voltage and current is required to obtain accurate results [11,12]. The approach based on power loss calculation calls for knowledge of the thermal impedance to achieve the loss/temperature profiles, because the IGBT electrical characteristics are functions of junction temperature [5]. Therefore, the practical implications of this method in a multi-device system are highly complicated because of the excessive use of data and short sample time [13].

Thus, the need for real-time and direct monitoring of the thermal load cycles of IGBT devices has made the heat flux sensor (HFS) an attractive approach to be adopted in wind power converters. The HFS allows online monitoring of the dissipated power of the IGBT module without interrupting the operation of the converter. Moreover, the HFS provides an opportunity to optimize the thermal performance by regulating the heat transfer [14].

Various HFS technologies have been developed so far. However, there are only two possible principles of operation: measuring the flux based on spatial temperature distribution or temporal temperature variations.

Currently, one of the available HFSs is the thermopile heat flux sensor $[15,16]$. Its operation is based on a spatial temperature gradient, where the temperature difference is measured by thermocouples bonded on both the upper and lower surfaces of the sensor. Thermocouples can be connected in series, thereby obtaining several thermoelectric junctions in order to amplify the voltage output.

A heat measuring method based on temperature transients is adopted by thin film resistance temperature devices (RTD), coaxial thermocouples, and calorimeters $[17,18]$. In order to measure the heat flux as a function of time, it is necessary to manage the temperature history by the methods discussed in [19]. The basic principle of the methods in [19] is based on the proportionality of the heat flux to the temperature gradient. However, it is difficult to obtain reliable measurements using these methods, since they assume a one-dimensional heat transfer and uniform temperature distribution as it changes only with time.

The present technologies associated with the HFS and heat measuring methods are implemented in a wide variety of industrial and research applications. Usually, the method of implementation involves mounting the sensor into or onto the surface of a solid material. Depending on the area of application, heat flux sensors are selected based on individual characteristics such as response time, sensitivity, experienced levels of temperatures, and heat flux. 
The aforementioned heat measurement techniques are widely used in the industry. However, their disadvantage is the indirect information of the heat flux. Either the temperature measured in the transient or the spatial temperature distribution require additional interpretation of the data. This study aims to adopt the heat flux measurements in a power device using a gradient heat flux sensor (GHFS). The GHFS allows direct measurements of the heat flux based on the Seebeck effect of the tilted layered materials. The structure of the sensor is provided by anisotropic thermoelements so that the thermoelectric electromotive Force (EMF) along the length of the sensor is achieved.

In this paper, the HFS is used to monitor the thermal stress of an IGBT module. Sine-wave-modulated current is applied to induce thermal load dynamics similar to the operation of the module in the wind power converter. Several steady state conditions are tested to compare the measured heat flux and the estimated IGBT power loss.

Section 2 describes the technology and basic characteristics of the GHFS. In Section 3, the focus is on the modeling of the spatial heat flux distribution within the module and possible heat power dissipated through the GHFS attached to the base plate of the IGBT. The application of the heat flux sensor in the test setup and an analysis of the test results are described in Sections 4 and 5, respectively. Interpretation and practical application of the obtained results are discussed in Section 6.

\section{Gradient Heat Flux Sensor Technology}

The thermoelectric effect induced in the material with a temperature gradient is called the Seebeck effect. Heat flux sensors based on the Seebeck effect are classified into longitudinal and transverse ones according to the direction of the induced thermo-EMF (Figure 1) [20,21]. In the longitudinal HFS (Figure 1a), the heat flow vector $\vec{q}$ and the vector of the thermo-EMF $\vec{E}_{\|}$are collinear. Thus, to increase the volt-watt sensitivity, the thickness of the sensor should be large enough (e.g., 1-2 mm). A relatively large thickness leads to two main drawbacks: a high thermal resistivity, which can reach the order of $10^{-3} \mathrm{~m}^{2} \cdot \mathrm{K} / \mathrm{W}$, and a slow time response (e.g., 10-100 s) [21].

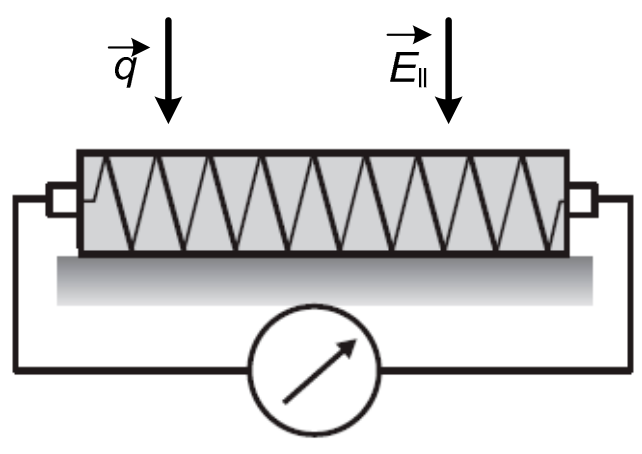

(a)

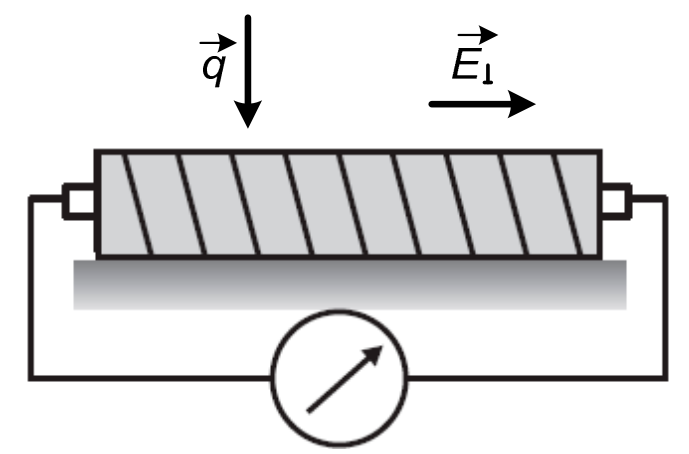

(b)

Figure 1. Heat flux sensors: (a) longitudinal; (b) and transverse [21]. Copyright Springer 2012.

The operation principle of the GHFS is based on the transverse Seebeck effect (Figure 1b). The sensitivity of the GHFS depends on the length of the sensor as the thermo-EMF $\vec{E}$ is induced in the direction normal to the heat flow $\vec{q}$. This effect is achieved by highly anisotropic thermoelements, whose crystallographic axis does not coincide with the geometrical axis of the sensor plate.

The current study focuses on the GHFS made of single-crystal bismuth. The artificial tilted layered material of the sensor yields the anisotropic properties of thermoelectric conductivity and the EMF induced in the material. The volt-watt sensitivity of such a sensor can be expressed as:

$$
S_{0}=\frac{E}{q A_{\text {sensor }}},
$$


where $E$ is the thermoelectric EMF, $q$ is the heat flux density, and $A_{\text {sensor }}$ is the area of the sensor plate. The sensitivity of the GHFS has been tested under different heat flux values and environmental conditions. The obtained sensitivity was constant, and the maximum calibration error was $0.64 \%$. The details of calibration process are described in [21].

The sensor is constructed of series-connected bismuth strips, where the width of a single strip is 0.1-0.2 mm (Figure 2) [22]. The thermo-EMF induced in a single bismuth plate is relatively low, and thus, the sensitivity can be increased by series connection.

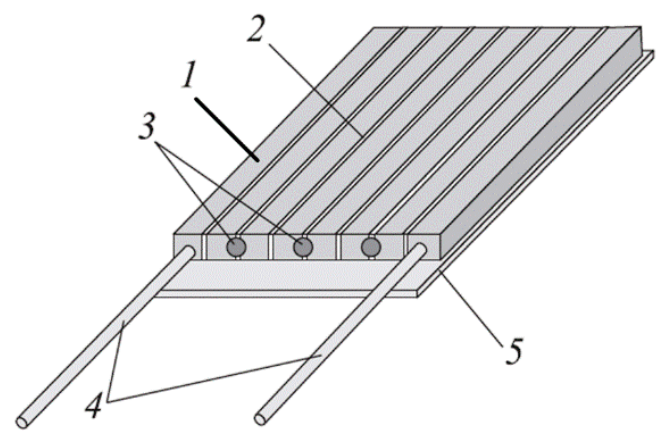

Figure 2. Bismuth-based gradient heat flux sensor, (1) single plate of bismuth; (2) insulation; (3) solder; (4) connecting terminals; (5) mica base [21]. Copyright Springer 2012.

The thermo-EMF of such a sensor (Figure 2):

$$
E_{\text {tot }}=q E S_{0} n
$$

where $n$ is the number of bismuth plates.

With the thermal conductivity of the bismuth material $7.45 \mathrm{~W} /(\mathrm{m} \cdot \mathrm{K})$ and the thickness of the plate $0.1-0.2 \mathrm{~mm}$, the thermal resistivity is in the order of $10^{-5} \mathrm{~m}^{2} \cdot \mathrm{K} / \mathrm{W}$. The maximum working temperature is limited by the melting point of bismuth, which is $544 \mathrm{~K}$.

In the tests performed in the current study, the GHFS has the thickness of $0.2 \mathrm{~mm}$, the volt-watt sensitivity of $15.9 \mathrm{mV} / \mathrm{W}$, and the area of $0.85 \mathrm{~cm}^{2}$. The response time of the sensor is in the range of $10^{-9}-10^{-8} \mathrm{~s}[20,22]$. However, considering the IGBT module as a system with a specific thermal impedance, the bandwidth of the measured heat flux dynamics is limited by the thermal transients associated with the heat flow from the chip to the base plate.

\section{Heat Flux Sensor Application in an IGBT Module for a Wind Power Converter}

The thermal load fluctuations of IGBTs in the modern large-scale wind power converters can be classified into several time domains with a specific time constant range and loading behavior [23,24]. In Figure $3 a$, the wind profile and the corresponding IGBT power loss dissipation in an Infineon FZ400R17KE4 IGBT module of a 3L ANPC converter prototype are shown. The results were obtained based on the $100 \mathrm{~kW}$ wind turbine modelled in Matlab Simulink. The thermal performance of the IGBT was analyzed using PLECS Blockset [25]. The dissipated heat power is averaged by the fundamental frequency of $50 \mathrm{~Hz}$. In Figure 3b, the instantaneous IGBT power losses in the steady state at the converter nominal power and the switching frequency of $2 \mathrm{kHz}$ are shown. Obviously, the IGBT thermal stress during the wind turbine operation is significant even for the dynamics associated with the stress drivers in different time domains.

In order to investigate the temperature and flux distribution inside the switch, the Finite Element Method (FEM) model of the module placed on an aluminum heat sink was generated in Comsol Multiphysics. The mesh of the FEM model has 920407 tetrahedral elements and the run time is $120 \mathrm{~s}$. 
The cross-section of the model is shown in Figure 4, and the characteristics of the materials used in the simulation are listed in Table 1.

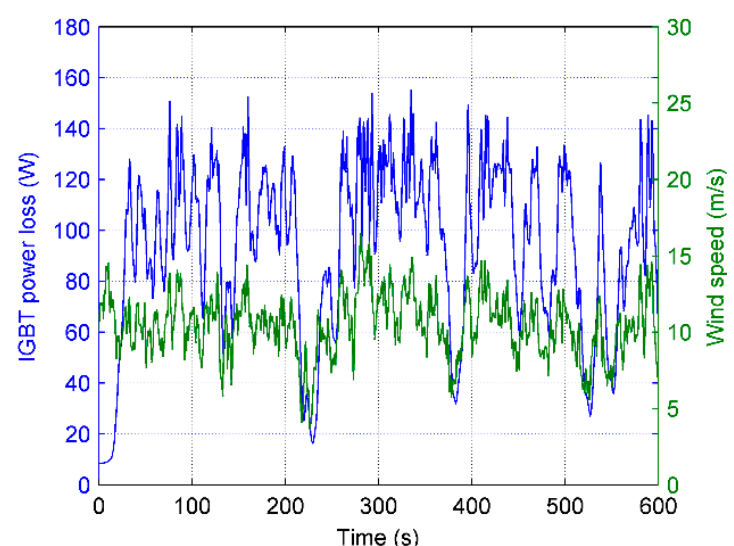

(a)

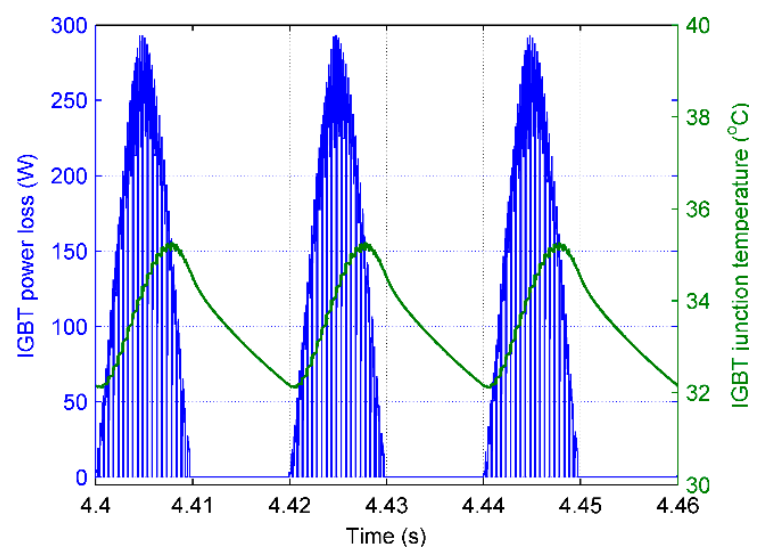

(b)

Figure 3. Wind speed and insulated-gate bipolar transistor (IGBT power losses: (a) averaged by the fundamental frequency $v$ s. time; (b) instantaneous IGBT power losses and junction temperature in the steady state.

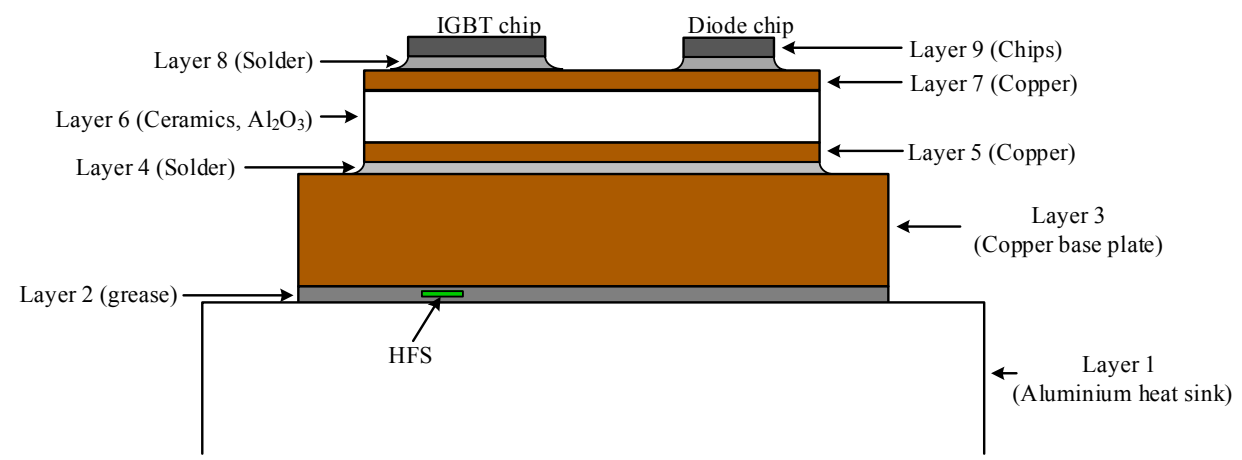

Figure 4. Cross-section of the model.

Table 1. Properties of the materials in the model.

\begin{tabular}{cccc}
\hline Layer & Material & Thickness, $\mathbf{m m}$ & Thermal Conductivity, W/(m· K) \\
\hline 1 & aluminum & 120 & 205 \\
2 & thermal grease & 1 & 1 \\
3 & copper & 3 & 400 \\
4 & solder & 0.08 & 50 \\
5 & copper & 0.15 & 400 \\
6 & $\mathrm{Al}_{2} \mathrm{O}_{3}$ & 0.42 & 27 \\
7 & copper & 0.15 & 400 \\
8 & solder & 0.08 & 50 \\
9 & silicon & 0.22 & 130 \\
\hline
\end{tabular}

In the model, the HFS is located in layer 2 and attached to the base plate. The thickness of the sensor is $0.2 \mathrm{~mm}$, and the thermal conductivity is $0.8 \mathrm{~W} /(\mathrm{m} \cdot \mathrm{K})$. Thermal grease is applied on both sides of the sensor so that it will be possible to attach the sensor to the surface of the base plate and the heat sink. Such a thick thermal grease layer was obtained because the practical task is also to attach the thermocouple of rather thick diameter, as discussed in Section 4. 
It is pointed out that the heat flow modeled here assumes that all heat from the chip is dissipated through the heat sink. In practical applications, as a result of the conduction heat transfer within the IGBT and the smaller thermal resistance in the direction from the chip to the heat sink, the majority of heat dissipates through the bottom side of the base plate. Furthermore, considering the path in the direction to the edge of the base plate, which has a smaller area than the bottom surface of the base plate, the heat transfer is determined by free (or natural) convection, and thus, the thermal resistance is much higher in this direction. The FEM modelling of the heat flux has shown that only $2 \%$ of the heat dissipates through the sides of the IGBT module, thus the free convection at the rim of the baseplate can be omitted. These facts makes it reasonable to attach the HFS to the bottom surface of the base plate.

In the FEM modelling, the ambient temperature is assumed to be $25{ }^{\circ} \mathrm{C}$. The heat generated in the IGBT $(13.2 \mathrm{~W})$ is dissipated from all four chips by forced convection from the fins of the heat sink, and the convective coefficient is $5 \mathrm{~W} /\left(\mathrm{m}^{2} \cdot \mathrm{K}\right)$. The surface temperature distribution is shown in Figure 5. The heat flux density through the thermal grease is shown in Figure 6, where the nonuniformity of the heat flux is observed. Thus, $13.2 \mathrm{~W}$ of the dissipated power in the IGBT corresponds to $33.2{ }^{\circ} \mathrm{C}$ of the chip temperature and $1870 \mathrm{~W} / \mathrm{m}^{2}$ of the heat density dissipated through the HFS. The average heat flux density over the base plate surface is $2025 \mathrm{~W} / \mathrm{m}^{2}$. Because the thermal conductivities of the thermal grease and the sensor are not the same, the heat flux through the HFS has an $8 \%$ lower density than the average density over the base plate. Obviously, the thermal conduction under the chip where the HPS is located is disturbed. In order to mitigate the disturbance of the heat conduction, a possible solution would be to place the HFS between the IGBT chips. However, in this case the influence of the other chips on the HFS should be considered. Another solution could be integrating the sensor close to the chip, but relatively low thermal conductivity and inappropriately high thickness of the sensor makes this solution unacceptable.

The thermal model of the IGBT is presented in Figure 6. It includes the thermal impedances of the junction to the case $Z_{j-\mathrm{c}}$, the case to the heat $\operatorname{sink} Z_{\mathrm{c}-\mathrm{h}}$, and the heat $\operatorname{sink}$ to the ambient $Z_{\mathrm{h}-\mathrm{a}}$. Because the HFS is attached on the surface of the base plate, the location of the heat flux measurement point is as indicated by $Q_{\text {meas }}$ in the thermal model. The thermal impedances of the FZ400R17KE4 IGBT module are presented in Table 2.

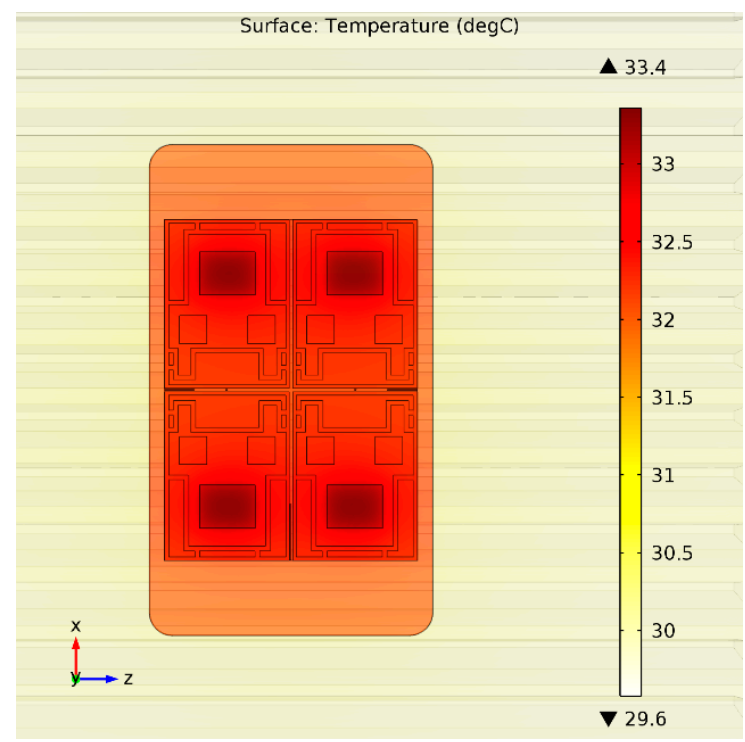

(a)

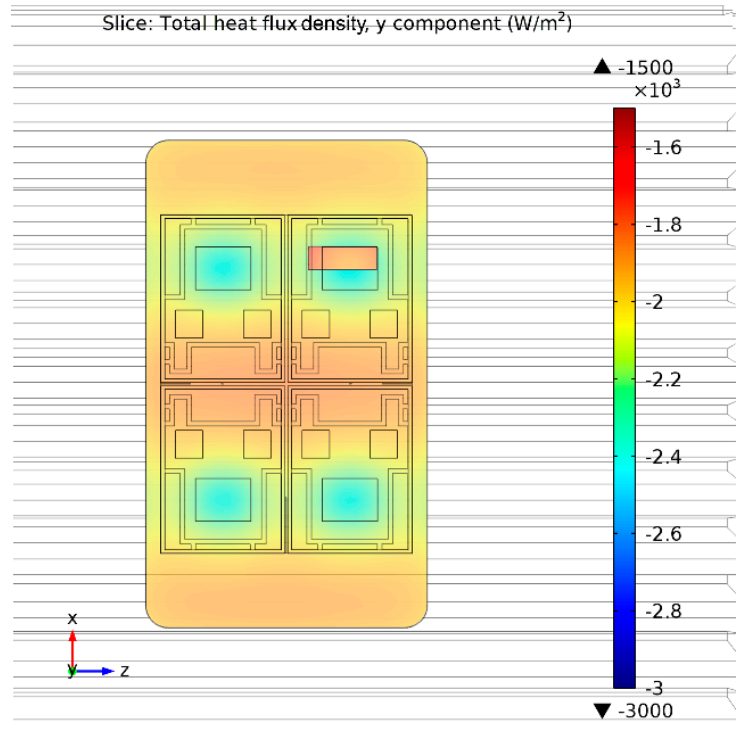

(b)

Figure 5. Top view of the model: (a) temperature distribution; (b) heat flux density distribution. 


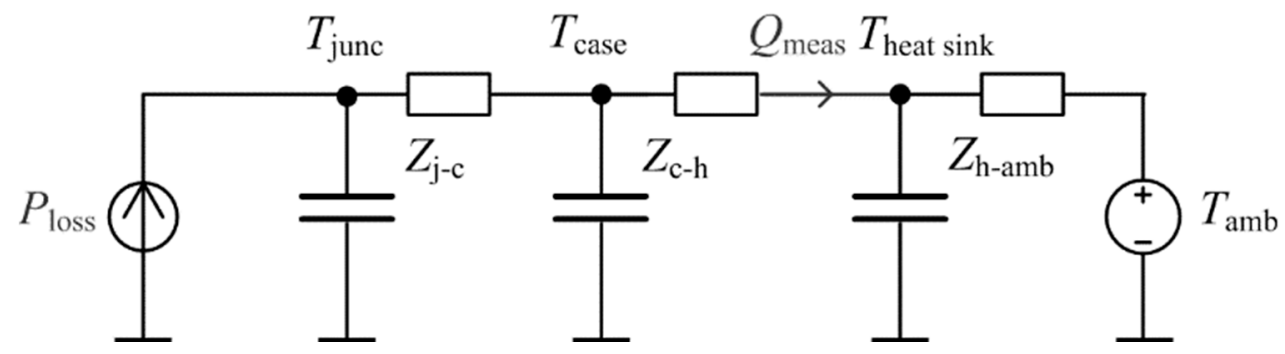

Figure 6. Thermal model of IGBT module.

Table 2. Thermal impedances of the FZ400R17KE4 IGBT module.

\begin{tabular}{|c|c|c|c|c|c|}
\hline \multirow{2}{*}{ Thermal Impedance } & \multicolumn{4}{|c|}{$Z_{j-c}$} & \multirow{2}{*}{$Z_{\mathrm{c}-\mathrm{h}}$} \\
\hline & Layer 1 & Layer 2 & Layer 3 & Layer 4 & \\
\hline$R_{\mathrm{iIGBT}}, \mathrm{K} / \mathrm{kW}$ & 2 & 9.2 & 42.6 & 6.3 & 18 \\
\hline$\tau_{\mathrm{iIGTB}}, \mathrm{ms}$ & 0.8 & 13 & 50 & 600 & - \\
\hline
\end{tabular}

\section{Heat Flux Sensor in the Test Setup}

The HFS has been tested to monitor the dissipated power of the Infineon FZ400R17KE4 IGBT module. Two IGBT modules are connected in parallel to the direct current (DC) voltage source (Figure 7). The operating switching algorithm of the IGBT is based on sinusoidal pulse-width modulation (PWM) with a $1 \mathrm{kHz}$ carrier and the fundamental frequencies of 0.1 and $7 \mathrm{~Hz}$. The gate driver provides inverse operation of two IGBTs. Numerical modeling of the scheme in Figure 7 is carried out using PLECS blockset in Matlab Simulink (Figure 8).

The DC voltage, the corresponding DC current, and the fundamental frequency of the IGBT control algorithm are the input parameters of the circuit, which were varied to achieve several steady state operating points. The fundamental frequency signal of the IGBT control algorithm is a rectified sine wave. Thus, the power loss in the IGBT S2 averaged by switching frequency is formed as half-wave sinusoids with the fundamental frequencies of 0.1 and $7 \mathrm{~Hz}$. Since, the IGBT S1 operates in an inverse mode, the corresponding power loss in $\mathrm{S} 1$ is formed as the inversed half-wave sinusoids.

The measurements obtained in the test were the collector-emitter voltage $V_{\mathrm{ce}}$, the collector current $I_{\mathrm{c}}$ of the $\mathrm{S}_{2}$ IGBT module, and the heat flux density $q$ measured by the GHFS. These signals were observed by a DL850 Scope Corder. In addition, the IGBT case temperature was measured using a T-type thermocouple, which was attached to the base plate using the thermal grease. The temperatures were observed in the LabView interface by a Keithley 2700 data logger.

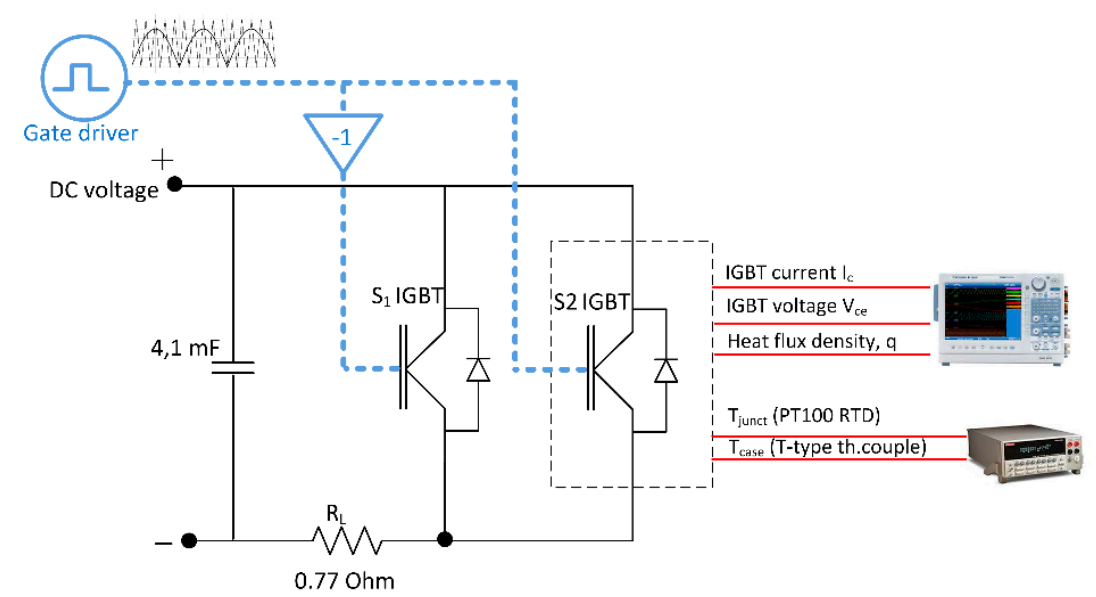

Figure 7. Test setup for the IGBT heat flux measurements. 


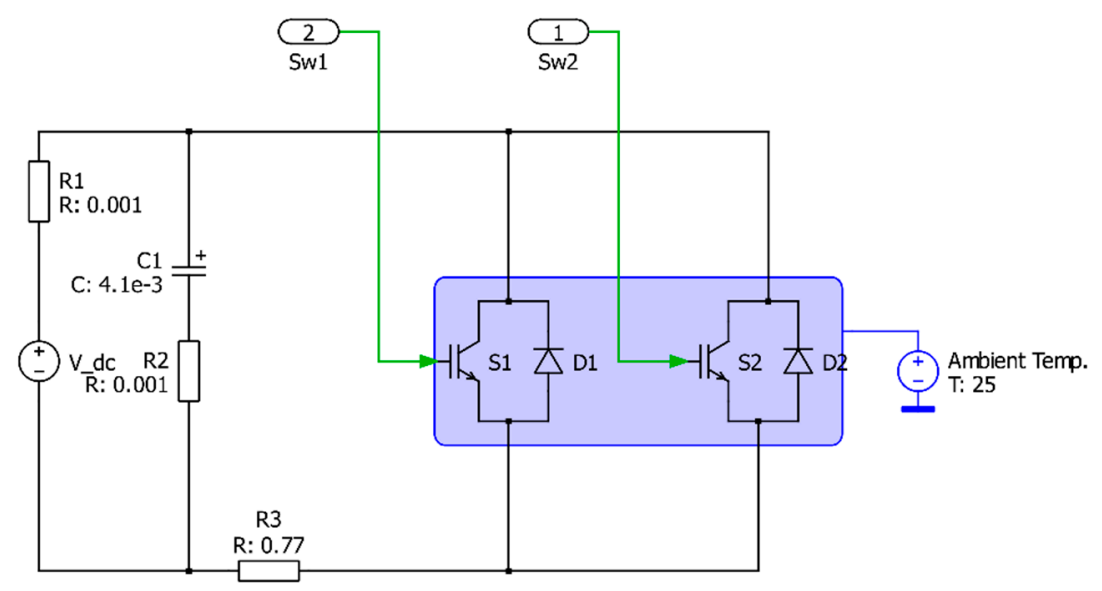

Figure 8. PLECS model for the IGBT heat flux measurements.

The collector-emitter voltage $V_{\text {ce }}$ and the collector current $I_{\mathrm{c}}$ of the IGBT were measured to obtain the instantaneous IGBT power loss $P_{\text {loss }}$ and to make a comparison with the heat flux $Q$.

Two IGBT modules were placed on the air-cooled heat sink. The GHFS was attached on the surface of the base plate of the $\mathrm{S}_{2}$ IGBT module using thermal grease (Figure 9). The position of the sensor was predefined based on the location of the four IGBT chips inside the module so that the sensor was placed under one of the IGBT chip positions.

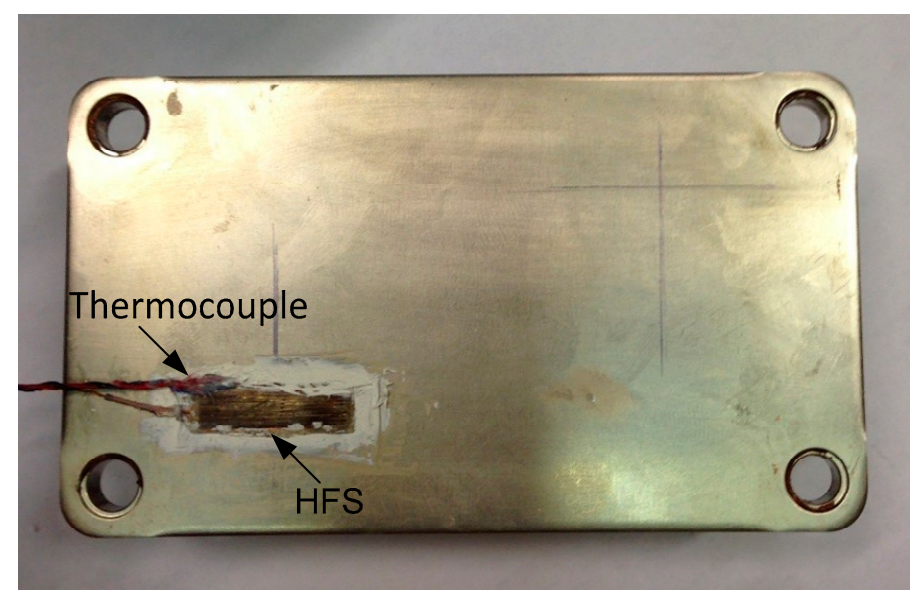

Figure 9. Attachment of the sensor to the base plate.

The induced EMF of the GHFS is in the range of millivolts. Thus, in order to detect the results by the DL850 Scope Corder, an amplifier connected to the GHFS terminals was used. The EMF was also measured by the Keithley 2700 data logger to record and visualize the heat flux density $q$ in the LabView interface.

Therefore, the induced thermoelectric EMF of the GHFS should be interpreted to the heat flux $Q$ determined from Equations (1) and (2) as follows:

$$
\begin{aligned}
& Q=q A_{\text {baseplate }} \\
& q=\frac{E_{\text {tot }}}{S_{0} A_{\text {sensor }}}
\end{aligned}
$$

where $Q$ is the heat flux $(\mathrm{W})$ and $A_{\text {baseplate }}$ is the area of the IGBT base plate $\left(\mathrm{m}^{2}\right)$. The extrapolation of the heat flux density in Equation (3) could cause an error in case of nonuniform heat flux distribution 
over the baseplate. The comparison of the heat flux test results with the numerical calculations are presented in Section 5.

The parameters used in the test are presented in Table 3.

Table 3. Heat flux sensor and IGBT parameters used for the heat flux calculation.

\begin{tabular}{cc}
\hline Parameter & Value \\
\hline$A_{\text {baseplate }}, \mathrm{cm}^{2}$ & 65.3 \\
$A_{\text {sensor }} \mathrm{cm}^{2}$ & 0.85 \\
$S_{0}, \mathrm{~V} / \mathrm{W}$ & $15.9 \times 10^{-3}$ \\
\hline
\end{tabular}

\section{Analysis of the Test Results}

The IGBT heat flux dissipation is observed in three steady state conditions, that is, with load currents of 15,30 , and $60 \mathrm{~A}$, which respectively correspond to $6.9,13.7$, and $29.5 \mathrm{~W}$ of the average dissipated IGBT power. Unfortunately, due to the voltage limit of the power source used, one cannot apply higher currents in the test setup. The heat flux density and the IGBT case temperature performance are visualized in a LabView interface (Figure 10). The case temperature and the heat flux have transient dynamics, due to the total thermal capacity of the system. It includes the convection properties of the cooler air and the thermal impedance from the case to the heat sink, and from the heat sink to the ambient environment.

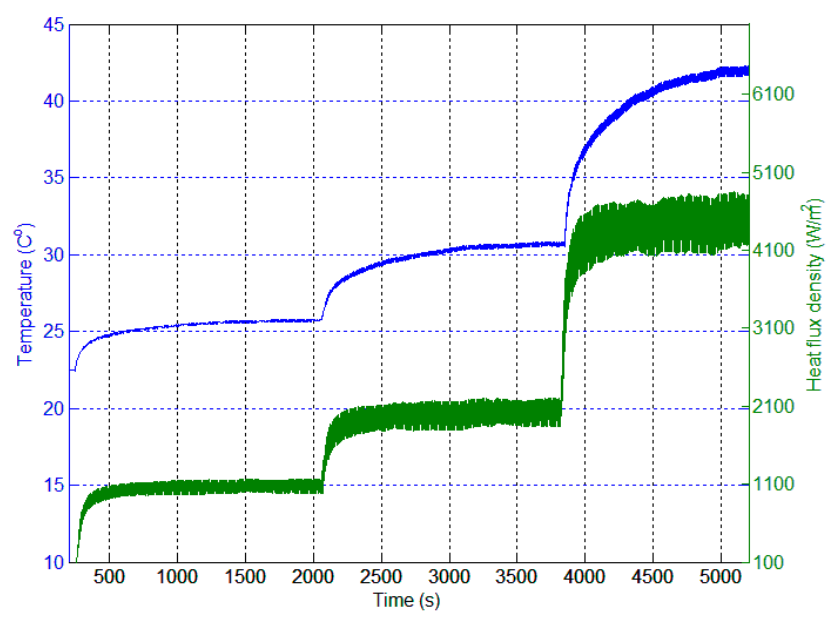

Figure 10. Heat flux density and case temperature in three steady state conditions measured at 15, 30, and $60 \mathrm{~A}$ switching current with fundamental and switching frequency of $0.1 \mathrm{~Hz}$ and $1 \mathrm{kHz}$, correspondingly.

In Figure 11, the measured heat flux densities at 0.1 and $7 \mathrm{~Hz}$ fundamental frequencies are presented. The heat flux density has a form of half-wave sinusoids with the periods of 10 and $0.14 \mathrm{~s}$, respectively. The heat flux density at $0.1 \mathrm{~Hz}$ was measured by the Keithley 2700 data logger with an average sampling time of $0.13 \mathrm{~s}$, and the heat flux density at $7 \mathrm{~Hz}$ was recorded by a DL850 Scope Corder with a $0.2 \mathrm{~ms}$ sampling time. Thus, significant noise content is visible at $7 \mathrm{~Hz}$.

The IGBT collector-emitter voltage $V_{\mathrm{ce}}$ and the collector current $I_{\mathrm{c}}$, measured within a $5 \mathrm{~ms}$ time to cover the IGBT switching are shown in Figure 12. The corresponding instantaneous and average power losses calculated based on $V_{\mathrm{ce}}$ and $I_{\mathrm{c}}$ and the measured heat loss $\mathrm{Q}$ are presented and shown to be equal. In Figure 13, the waveforms of the IGBT power losses modeled in PLECS (Figure 9), averaged by the switching frequency at 15,30, and 60 A load current, are presented. Here, the power losses are formed as half-waves of sinusoids. The average values at 15, 30, and $60 \mathrm{~A}$ are 6.9, 13.7, and $29.5 \mathrm{~W}$, respectively. 
$0.1 \mathrm{~Hz}, 15 \mathrm{~A}$
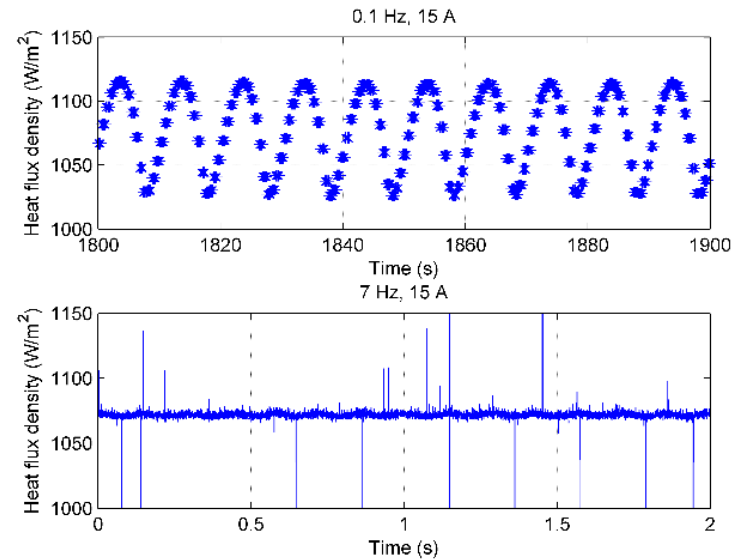

Figure 11. Heat flux at $0.1 \mathrm{~Hz}$ and $7 \mathrm{~Hz}$ with $15 \mathrm{~A}$ source current.
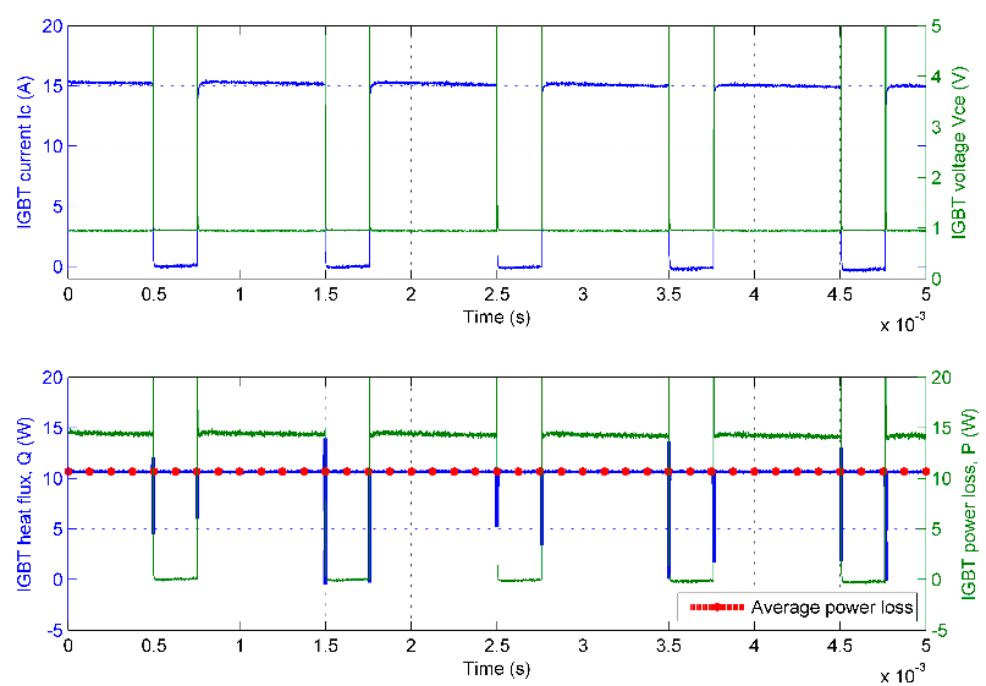

Figure 12. Collector-emitter voltage $V_{\mathrm{ce}}$, collector current $I_{\mathrm{c}}$, instantaneous and average IGBT power loss $P$, and heat flux $Q$ within $5 \mathrm{~ms}$ period.
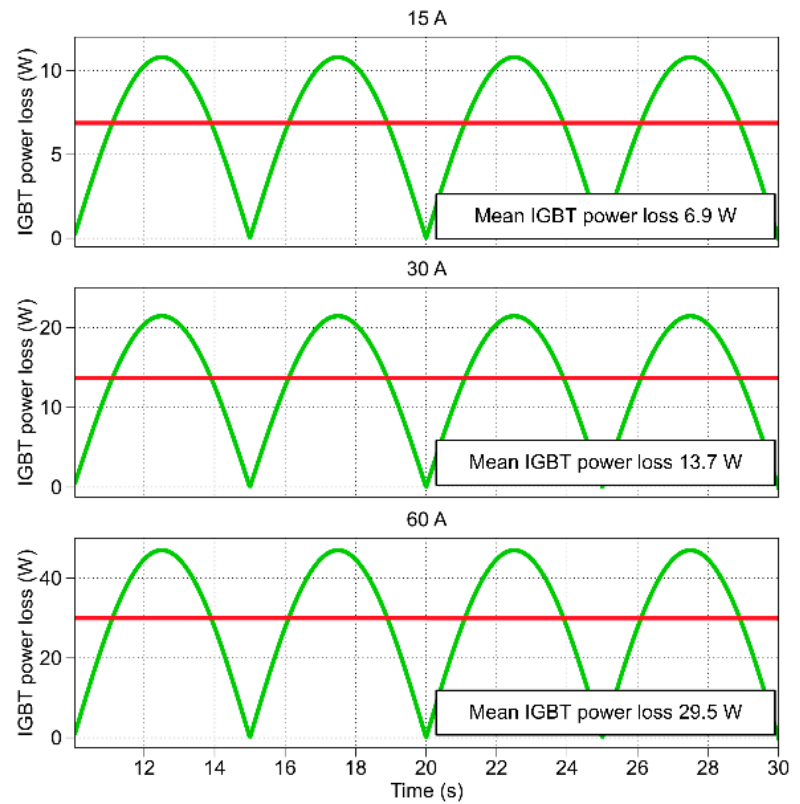

Figure 13. IGBT power losses averaged by the switching frequency at 15, 30, and $60 \mathrm{~A}$. 
No high switching frequency variation can be observed in the measured heat power because of the thermal impedance $Z_{j-c}$ of the IGBT from the junction to the case (Figure 6). Therefore, to compare the performance of the heat flux in steady state conditions, it is advisable to define both the heat flux $Q$ and the power loss $P_{\text {loss }}$ averaged by the fundamental frequency.

The calculated IGBT power losses $P_{\text {loss }}$ and the measured heat flux $Q$, both averaged by the fundamental frequency of $0.1 \mathrm{~Hz}$, are presented in Table 4. Thus, in the 15, 30, and 60 A steady states, the differences between $P_{\text {loss }}$ and $Q$ are $1.1 \%, 3.5 \%$, and $3.7 \%$, respectively.

Table 4. Comparison of the heat flux test results with the power loss defined by numerical modeling in Matlab PLECS.

\begin{tabular}{cccc}
\hline Compared Signals & \multicolumn{3}{c}{ Steady State Conditions, DC Current } \\
\cline { 2 - 4 } & $\mathbf{1 5 ~ \mathbf { A }}$ & $\mathbf{3 0 ~ \mathbf { A }}$ & $\mathbf{6 0 ~ A}$ \\
\hline $\begin{array}{c}\text { Power loss } P_{\text {loss averaged by fundamental }} \\
\text { frequency, W (modeled by Matlab PLECS) }\end{array}$ & 6.90 & 13.68 & 29.50 \\
\hline $\begin{array}{c}\text { Measured heat flux } Q \text { averaged by } \\
\text { fundamental frequency, W }\end{array}$ & 6.98 & 13.20 & 28.40 \\
\hline
\end{tabular}

The measured heat flux density $q$ is compared with the results of the FEM modeling in Table 4 . The modeled results indicate that the heat flux through the HFS has a $6.6 \%-8 \%$ lower density compared with the density averaged over the whole base plate (Figure 6). As mentioned in Section 3, this finding can be explained by the difference in the thermal conductivities between the HFS $(0.8 \mathrm{~W} /(\mathrm{m} \cdot \mathrm{K}))$ and the thermal grease $(1 \mathrm{~W} /(\mathrm{m} \cdot \mathrm{K}))$, which results in the distortion of the heat flux distribution over the base plate. However, the measured heat flux density results are similar to the modeled averaged density (Table 5).

Table 5. Comparison of the heat flux density test results with the numerical modeling.

\begin{tabular}{|c|c|c|c|c|}
\hline \multirow{2}{*}{\multicolumn{2}{|c|}{ Compared Signals }} & \multicolumn{3}{|c|}{ Steady State Conditions, DC Current } \\
\hline & & $15 \mathrm{~A}$ & $30 \mathrm{~A}$ & $60 \mathrm{~A}$ \\
\hline \multirow{2}{*}{$\begin{array}{l}\text { Heat flux density (FEM } \\
\text { model), } q_{\text {FEM }} \mathrm{W} / \mathrm{m}^{2}\end{array}$} & Through HFS & 992 & 1870 & 4060 \\
\hline & Average over base plate & 1075 & 2025 & 4332 \\
\hline \multicolumn{2}{|c|}{ Measured heat flux density $q, \mathrm{~W} / \mathrm{m}^{2}$} & 1074 & 2025 & 4347 \\
\hline
\end{tabular}

Notes: HFS refers to heat flux sensor.

It should be noted that the small variations in the model parameters and the test setup, such as the thickness of the grease layer and the thermal conductivities of the material, could produce significant deviation to the chip temperature and the heat flux density distribution over the base plate.

\section{Interpretation and Practical Application of the Results}

According to the experimental results, it can be concluded that the heat flux variations have a limited bandwidth that depends on the IGBT thermal impedance and the module package properties. The results observed at $7 \mathrm{~Hz}$ support the latter statement because of the extremely small amplitude of the sine-wave heat flux density. Therefore, the IGBT power loss oscillations corresponding to the IGBT switching and the variations in the $50 \mathrm{~Hz}$ load current cannot be tracked by the HFS. However, modern variable-speed wind turbines involve the operation of the generator-side inverters at lower frequencies. In doubly-fed drives, in particular, the rotational speed and the corresponding fundamental frequency of the load current are limited to around $\pm 30 \%$ of their synchronous values [26]. Thus, at low operating frequencies, the IGBT thermal impedance has a lower attenuation effect on thermal cycling than at the $50 \mathrm{~Hz}$ operating frequency. 
The HFS can be applied to indicate an IGBT failure associated with degradation. As mentioned above, the typical package-related failure mechanism, such as solder degradation, induces localized heating as a result of a rise in the thermal resistance [27]. The voiding effect, both under the silicon chip or the ceramic substrate, causes an uneven heat distribution over the chip or base plate surface, which may lead to a higher localized heat flux density. Measured heat flux density can be compared with the expected power losses of an appropriately functioning IGBT in order to observe a possible deviation. However, in order to provide online calculation of the expected power loss, knowledge of the current operating point is required. For this purpose, the electrical variables from the wind turbine data acquisition system, such as load current, the DC link voltage, the power factor, and the fundamental and switching frequencies, are needed. The measurement of all electrical parameters can be avoided if the correlation between the load current and the heat flux can be determined in advance. The deviation from the correlations would mean the degradation of the device. Because of the difference in the time constants of the IGBT power losses and the heat flux, it is reasonable to compare the signals averaged by the fundamental frequency. If a deviation is detected, one can conclude that degradation has taken place. This deviation can also be a result of another failure mechanism observed in actual systems [28,29], which is thermal grease degradation. The mechanisms such as the grease pump-out and dry-out also induce an increase in the grease thermal resistance [30] and the heat flux through the HFS.

As mentioned in Section 5, another attractive application of the HFS is the option to optimize the IGBT thermal performance. In particular, heat flux measurements can be used as a feedback signal for a cooling control system. In [14], the power losses of the device measured by the HFS were used to control the fluid flow rate in the liquid cooling systems. The purpose of the study [14] was to smooth the heat sink temperature during the variable load and thereby prolong the lifetime.

\section{Conclusions}

In this paper, an application of the HFS based on the transverse Seebeck effect in wind power electronics was described. The operation of the sensor was tested in an IGBT-based test setup. The control algorithm for the IGBT switches was programmed to generate output IGBT power loss dynamics resembling the operation in a wind turbine converter. In order to implement direct measurements of the heat flux dissipation of the IGBT, an HFS was attached onto the surface of the IGBT base plate using thermal grease. The HFS was placed under one of the four chips on the base plate. The heat flux performance was tested in steady state conditions. DC currents of 15, 30, and $60 \mathrm{~A}$ induced sine-wave IGBT heat dissipation of $6.98,13.2$, and $28.40 \mathrm{~W}$, respectively, averaged by fundamental frequency. The measured average IGBT power loss deviates from the thermal model calculated in Matlab PLECS by $3.7 \%$ at the maximum.

The measured and FEM simulation results were compared in terms of heat flux density based on the model analyzed in Comsol Multiphysics, where the heat flux dissipation from the chip to the heat sink was assumed. The measured heat flux density was $8 \%$ higher than the density of the modeled heat flux through the sensor. However, the averaged heat flux density over the base plate was equal to the measured one. Here, it is pointed out that the distribution of the heat flux density over the base plate is highly dependent on the thermal conductivities, and the thickness of the thermal grease and the HFS.

The paper shows good results of direct measurements of the IGBT heat dissipation using the HFS, which can be an attractive and innovative approach to the thermal stress condition monitoring (CM). Heat flux measurements provide an opportunity to improve the reliability performance of the IGBT and provide online detection of the device aging or failure during wind turbine operation. By heat flux measurements, the thermal performance can be optimized and the lifetime of the device can be extended.

Acknowledgments: This work was funded by Electrical Engineering Department, Lappeenranta University of Technology. 
Author Contributions: Kirill Murashko designed the test setup; Raimo Juntunen programmed the IGBT module switching algorithm; Elvira Baygildina and Liudmila Smirnova performed the experiments and analyzed the data; Andrey Mityakov, Vladimir Mityakov, and Sergey Sapozhnikov provided the gradient heat flux sensor; Mikko Kuisma provided the amplifier; Olli Pyrhönen, Pasi Peltoniemi, and Katja Hynynen gave useful suggestions and revised the manuscript; Elvira Baygildina wrote the paper.

Conflicts of Interest: The authors declare no conflict of interest.

\section{Abbreviations}

The following abbreviations are used in this manuscript:

$\begin{array}{ll}\text { CM } & \text { Condition Monitoring } \\ \text { CTE } & \text { Coefficients of Thermal Expansion } \\ \text { DC } & \text { Direct Current } \\ \text { DCB } & \text { Direct Copper Bonded } \\ \text { EMF } & \text { Electromotive Force } \\ \text { FEM } & \text { Finite Element Method } \\ \text { GHFS } & \text { Gradient Heat Flux Sensor } \\ \text { HFS } & \text { Heat Flux Sensor } \\ \text { IGBT } & \text { Insulated-gate Bipolar Transistor } \\ \text { IR } & \text { Infrared } \\ \text { PWM } & \text { Pulse-Width Modulation } \\ \text { RTD } & \text { Resistance Temperature Device } \\ \text { TSEP } & \text { Temperature Sensitive Electrical Parameter }\end{array}$

\section{References}

1. Ma, K.; Blaabjerg, F.; Liserre, M. Thermal Analysis of Multilevel Grid-Side Converters for 10-MW Wind Turbines under Low-Voltage Ride Through. IEEE Trans. Ind. Appl. 2013, 49, 909-921. [CrossRef]

2. Ma, K.; Blaabjerg, F.; Liserre, M. Reactive Power Influence on the Thermal Cycling of Multi-MW Wind Power Inverter. IEEE Trans. Ind. Appl. 2013, 49, 922-930. [CrossRef]

3. Ikonen, M. Power Cycling Lifetime Estimation of IGBT Power Modules Based on Chip Temperature Modeling. Ph.D. Thesis, Lappeenranta University of Technology, Lappeenranta, Finland, 2012.

4. Ciappa, M. Selected failure mechanisms of modern power modules. Microelectron. Reliab. 2002, 42, 653-667. [CrossRef]

5. Ma, K.; Bahman, A.S.; Beczkowski, S.; Blaabjerg, F. Complete Loss and Thermal Model of Power Semiconductors Including Device Rating Information. IEEE Trans. Power Electron. 2015, 30, 2556-2569. [CrossRef]

6. Kostandyan, E.E.; Sørensen, J.D. Reliability Assessment of solder joints in power electronics modules by crack damage model for wind turbine applications. Energies 2014, 4, 2236-2248. [CrossRef]

7. Avenas, Y.; Dupont, L.; Khatir, Z. Temperature Measurement of Power Semiconductor Devices by Thermo-Sensitive Electrical Parameters-A Review. IEEE Trans. Power Electron. 2012, 27, 3081-3092. [CrossRef]

8. Blackburn, D.-L. Temperature measurements of semiconductor devices-A review. In Proceedings of the 20th Annual Semiconductor Thermal Measurement and Management Symposium, San Jose, CA, USA, 9 March-11 March 2004; pp. 70-80.

9. Baker, N.; Munk-Nielsen, S.; Liserre, M.; Iannuzzo, F. Online junction temperature measurement via internal gate resistance during turn-on. In Proceedings of the European Conference on Power Electronics and Applications (EPE 2014), Lappeenranta, Finland, 26-28 August 2014; pp. 1-10.

10. Ammous, A.; Allard, B.; Morel, H. Transient Temperature Measurements and Modeling of IGBT's Under Short Circuit. IEEE Trans. Power Electron. 1998, 13, 12-25. [CrossRef]

11. Ghimire, P.; de Vega, A.R.; Beczkowski, S.; Munk-Nielsen, S.; Rannested, B.; Thogersen, P.B. Online Vce measurement and temperature estimation method for high power IGBT module in normal PWM operation. In Proceedings of the International Power Electronics Conference (IPEC-Hiroshima 2014-ECCE-ASIA), Hiroshima, Japan, 18-21 May 2014; pp. 2850-2855.

12. Automated Power Loss Characterization of High Power IGBT Modules. Available online: http:/ / www.corpe.et.aau.dk/laboratory-facilities / Automated+Power+Loss+Characterization+of+ High+Power+IGBT+Modules/ (accessed on 29 January 2016). 
13. Zhou, Z.; Knanniche, M.S.; Igic, P.; Kong, S.T.; Towers, M.; Mawby, P.A. A fast power loss calculation method for long real time thermal simulation of IGBT modules for a three/phase inverter system. In Proceedings of the European Conference on Power Electronics and Applications (EPE 2005), Dresden, Germany, 11-14 September 2005; pp. 1-10.

14. Smirnova, L. Electromagnetic and Thermal Design of a Multilevel Converter with High Power Density and Reliability. Ph.D. Thesis, Lappeenranta University of Technology, Lappeenranta, Finland, 2015.

15. Olivier, H. Thin Film Gauges and Coaxial Thermocouples for Measuring Transient Temperatures; Shock Wave Laboratory: Aachen, Germany, 2003.

16. RdF Heat Flux Sensors. Available online: http://www.rdfcorp.com/products/hflux/hfs-c_01.shtml (accessed on 29 January 2016).

17. Hogendoorn, C.J.; de Lange, H.C.; van Steenhoven, A.A. Design optimization for fast heat-transfer gauges. Meas. Sci. Technol. 1998, 9, 428-434. [CrossRef]

18. Kidd, C.T.; John, C.; Adams, J. Fast response heat-flux sensor for measurement commonality in hypersonic wind tunnels. J. Spacecr. Rockets 2001, 38, 719-729. [CrossRef]

19. Webster, J.G. Handbook for Measurement, Instrumentation and Sensors; CRC Press LLC: Boca Raton, FL, USA, 1999; pp. 1130-1139.

20. Mityakov, A.V.; Sapozhnikov, S.Z.; Mityakov, V.Y.; Snarskii, A.A.; Zhenirovsky, M.I.; Pyrhönen, J.J. Gradient heat flux sensors for high temperature environments. Sens. Actuators 2012, 176, 1-9. [CrossRef]

21. Sapozhnikov, S.Z.; Mityakov, V.Y.; Mityakov, A.V.; Pokhodun, A.I.; Sokolov, N.A.; Matveev, M.S. The calibration of gradient heat flux sensors. Meas. Tech. 2012, 54, 1155-1159. [CrossRef]

22. Sapozhnikov, S.Z.; Snarskii, A.A.; Mityakov, V.Y.; Zhenirovsky, M.I.; Mityakov, A.V. Gradient heat flux sensors based on the artificial anisotropic thermoelements. Thermoelectricity 2010, 4, 38-53.

23. Ma, K.; Liserre, M.; Blaabjerg, F.; Kerekes, T. Thermal Loading and Lifetime Estimation for Power Device Considering Mission Profiles in Wind Power Converter. IEEE Trans. Power Electron. 2015, 30, 590-602. [CrossRef]

24. Baygildina, E.; Smirnova, L.; Ma, K.; Peltoniemi, P.; Pyrhönen, O. Power semiconductor lifetime estimation considering dynamics of wind turbine. In Proceedings of the Power Electronics and Machines for Wind and Water Applications IEEE Symposium (PEMWA), Milwaukee, WI, USA, 24-26 July 2014; pp. 1-6.

25. User Manual of PLECS Blockset; version 3.7; Plexim GmbH: Zürich, Switzerland, 2015; Available online: http://www.plexim.com/files/plecsmanual.pdf (accessed on 28 April 2016).

26. Akhmatov, V. Variable-speed wind turbines with doubly-fed induction generators. Part I: Modelling in dynamic simulation tools. J. Wind Eng. 2002, 26, 85-108. [CrossRef]

27. Yang, S.; Xiang, D.; Bryant, A.; Mawby, P.; Ran, L.; Tavner, P. Condition Monitoring for device reliability in power electronic converters: A review. IEEE Trans. Power Electron. 2010, 25, 2734-2752. [CrossRef]

28. Perpina, X.; Navarro, L.; Jorda, X.; Vellvehi, M.; Serviere, J.-F.; Mermet-Guyennet, M. Reliability and Lifetime Prediction for IGBT Modules in Railway Traction Chains. In Reliability and Safety in Railway; Perpinya, X., Ed.; InTech: Rijeka, Croatia, 2012; pp. 193-222.

29. Fischer, K.; Stalin, T.; Ramberg, H.; Thiringer, T.; Wenske, J.; Karlsson, R. Investigation of Converter Failure in Wind Turbines; Elforsk AB: Stockholm, Sweden, 2012.

30. Skuriat, R.; Li, J.F.; Agyakwa, P.A.; Mattey, N.; Evans, P.; Johnson, C.M. Degradation of thermal interface materials for high-temperature power electronics applications. Microelectron. Reliab. 2013, 53, $1933-1942$. [CrossRef]

(C) 2016 by the authors; licensee MDPI, Basel, Switzerland. This article is an open access article distributed under the terms and conditions of the Creative Commons Attribution (CC-BY) license (http://creativecommons.org/licenses/by/4.0/). 